\title{
ENERGY MEASUREMENTS OF PROTON RESONANCES IN LIGHT NUCLEI
}

\author{
by J. KUPERUS, P. J. M. SMULDERS and P. M. ENDT \\ Fysisch Laboratorium der Rijksuniversiteit, Utrecht, Nederland
}

\section{Synopsis}

A search has been made for $(p, \gamma)$ resonances in all stable nuclides from ${ }^{19} \mathrm{~F}$ through ${ }^{33 S}$ for proton energies in the $0.20-0.85 \mathrm{MeV}$ range. The energies of eighty-one resonances were measured with an average precision of 0.24 percent. Four new resonances, at $431.0 \pm 1.3,436.9 \pm 1.3,480.1 \pm 1.0$, and $725.5 \pm 1.2 \mathrm{keV}$, were observed in the ${ }^{22} \mathrm{Ne}(p, \gamma)^{23} \mathrm{Na}$ reaction, and one new resonance, at $501.4 \pm 1.4 \mathrm{keV}$, was found in the ${ }^{25 \mathrm{Mg}}(p, \gamma)^{26} \mathrm{Al}$ reaction.

1. Introduction. The first relatively extensive experimental survey of $(p, \gamma)$ resonances below $E_{p}=500 \mathrm{keV}$ in light nuclides has been performed by Tangen ${ }^{31}$ ). Since then separated isotopes have become available and the measurements have been extended to higher proton energies ${ }^{2}$ ) ${ }^{13}$ ). In several of these later investigations the proton energy resolution and, consequently, the precision in the resonance energies reported, has been low. In some reactions the experimental error was only slightly smaller than the average distance of resonances, which makes the proper classification and tabulation of these resonances difficult.

In the present investigation the resonance energies have been measured of 81 resonances for target nuclides in the ${ }^{19} \mathrm{~F}$ through ${ }^{33} \mathrm{~S}$ region and for proton energies up to $850 \mathrm{keV}$. The average experimental error amounts to 0.24 percent. The work was started mainly to obtain a good calibration for the analysing magnet. However, it appeared that without very much more work the whole $A=19-33$ region could be covered.

2. Experimental procedure. Protons were accelerated with the Utrecht $850 \mathrm{kV}$ Cockroft-Walton generator and analysed with a 90 degree magnet of $20 \mathrm{~cm}$ orbit radius. The magnetic field was measured with a nuclear resonance gaussmeter. The gamma-ray yield was determined with a scintillation counter.

If a resonance at proton energy $E$ is observed at a gaussmeter frequency $v$ one has the relation $\nu^{2}=K E$, in which $K$ is the calibration constant of the magnet. This constant was determined by observation of a number of resonances with energies accurately determined by others (see $\S 3$ ). 
Of course, the relation $\nu^{2}=K E$ is not relativistically correct. If, however, it is assumed that the calibration energies used were corrected for relativistic effects, the errors made in applying the non-relativistic relation both in the calibration and in the measurement of a resonance energy, not used in the calibration, cancel to some extent. The remaining error, being several times smaller than the experimental error in the whole region of proton energies considered here, can then be neglected.

All measurements were performed with targets which were several times thicker than both the beam energy spread and the natural width of the resonance. Actually, the natural width is negligible for all resonances but for those in the $\mathrm{F}^{19}(p, \alpha \gamma)$ reaction. For thick targets the resonance shows a fairly steep low-energy edge, a more or less flat top and a gently sloping high-energy edge. The difference in steepness of the front and the back slopes is caused by the energy straggle introduced by the fact that not all protons having penetrated in the target to a certain depth have lost the same energy. It can easily be proved that the resonance energy is given by the point on the low-energy slope where the yield has risen to half the maximum value, if it is assumed that the beam energy spread at the surface of the target is a symmetric function, and that the target is infinitely thick. The errors introduced by incomplete fulfilment of any of these two conditions are several times smaller than the error (see below) assigned to the measured resonance energies.

Most targets were prepared by evaporation in vacuo of the element or of a suitable compound onto $1 / 2 \mathrm{~mm}$ copper backings. In this way targets of $\mathrm{CaF}_{2}, \mathrm{NaBr}, \mathrm{Mg}, \mathrm{MgO}, \mathrm{Al}, \mathrm{SiO}_{2}, \mathrm{Zn}_{3} \mathrm{P}_{2}$, and $\mathrm{ZnS}$ were obtained. Also enriched ${ }^{21} \mathrm{Ne},{ }^{22} \mathrm{Ne},{ }^{25} \mathrm{Mg},{ }^{26} \mathrm{Mg},{ }^{29} \mathrm{Si},{ }^{30} \mathrm{Si}$, and $\mathrm{Cd}^{33} \mathrm{~S}$ targets have been used, obtained from the Atomic Energy Research Establishment, Harwell, England. The neon targets were of the absorption type, made by bombarding a nickel backing with the mass separator beam. Targets of the latter type were also kindly supplied by the Laboratorium voor Massaspectrografie in Amsterdam.

Carbon build-up on the target presents a special problem in precision measurements of resonance energies. This effect was very much reduced by the use of a suitably designed cold trap in front of the target, and by making exclusive use of freshly prepared targets. By remeasuring the first resonance after a run consisting of measurements on several resonances possible carbon build-up can be detected through a shift of the resonance energy. All shifts observed were several times smaller than the error finally assigned to the measured resonance energies.

The steepness of the low-energy slope of a resonance is a good measure of the quality of a target. For a perfectly homogeneous thick target and for an infinitely narrow resonance the steepness is determined only by the beam energy spread. With narrow energy defining slits of equal width $s$ 
TABLE I

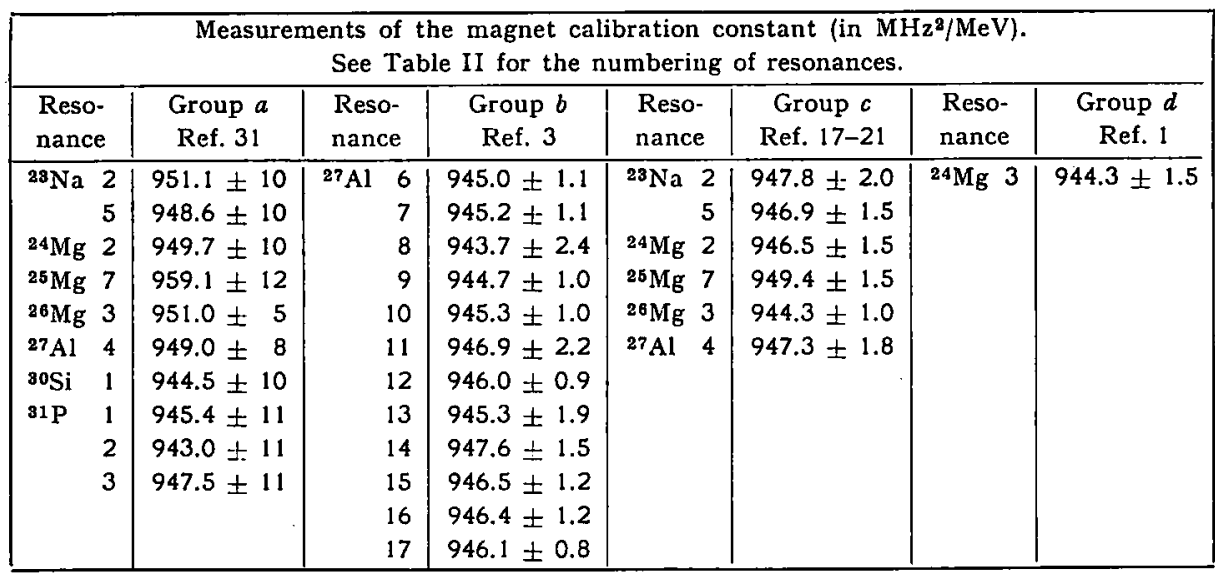

\begin{tabular}{|c|c|c|c|c|}
\hline group & average & $\begin{array}{c}\text { internal } \\
\text { error }\end{array}$ & $\begin{array}{c}\text { external } \\
\text { error }\end{array}$ & final error \\
\hline$a$ & 949.3 & 2.8 & 1.2 & 2.8 \\
$b$ & 945.7 & 0.3 & $0.2^{4}$ & 0.5 \\
$c$ & 946.4 & 0.6 & 0.8 & 0.8 \\
$d$ & 944.3 & 1.5 & - & 1.5 \\
\hline \multicolumn{2}{|c|}{ Final average: } & & & \\
\multicolumn{2}{|c|}{945.9} & 0.4 & 0.4 & 0.4 \\
\hline
\end{tabular}

(in $\mathrm{mm}$ ), placed at the entrance and exit of the analysing magnet $(r=20$ $\mathrm{cm})$, the beam energy distribution at the target can be regarded as triangular with a base width equal to $s E / 200$. For this ideal case the steepness of the low-energy slope of a resonance, expressed e.g. as the interquartile range, i.e. the energy interval between the points of $25 \%$ and $75 \%$ of the maximum yield, is given by $\Delta E=s E\left(1-\frac{1}{2} \sqrt{2}\right) / 200$. For all resonances the interquartile range as actually observed, $\Delta E_{\text {obs }}$, was compared to $\Delta E_{\text {theor }}$.

For calibration purposes only those resonances were accepted for which the ratio $\Delta E_{\text {obs }} / \Delta E_{\text {theor }}$ came out smaller than 2 . The error finally assigned to a measured resonance energy, apart from the error in the calibration constant, was taken equal to $\Delta E_{\text {obs. }}$. This must be considered as a quite conservative limit, amply taking care of all sources of error mentioned above. Measurements performed at different times and with different targets on the same resonance never differed by more than this error. Only for the ${ }^{19} \mathrm{~F}$ resonances numbered $2,3,5$, and 6 (see Table II) which have a large natural width a smaller error has been taken, corresponding to a frequency error of $20 \mathrm{kHz}$.

In Fig. 1 the $453 \mathrm{keV}{ }^{26} \mathrm{Mg}(p, \gamma)^{27} \mathrm{Al}$ resonance is shown as measured with slits of $0.75,1.5$, and $3.0 \mathrm{~mm}$, respectively. It is seen that the halfmaximum yield points coincide within $0.1 \mathrm{keV}$. The values of $\Delta E_{\text {obs }} / \Delta E_{\text {theor }}$ 
are $1.0,0.8$, and 0.65 , respectively. That for the wider slits these values come out smaller than unity, indicates that the wide slits are not completely filled by the beam. In all measurements reported below slits of $0.75 \mathrm{~mm}$ width have been used.

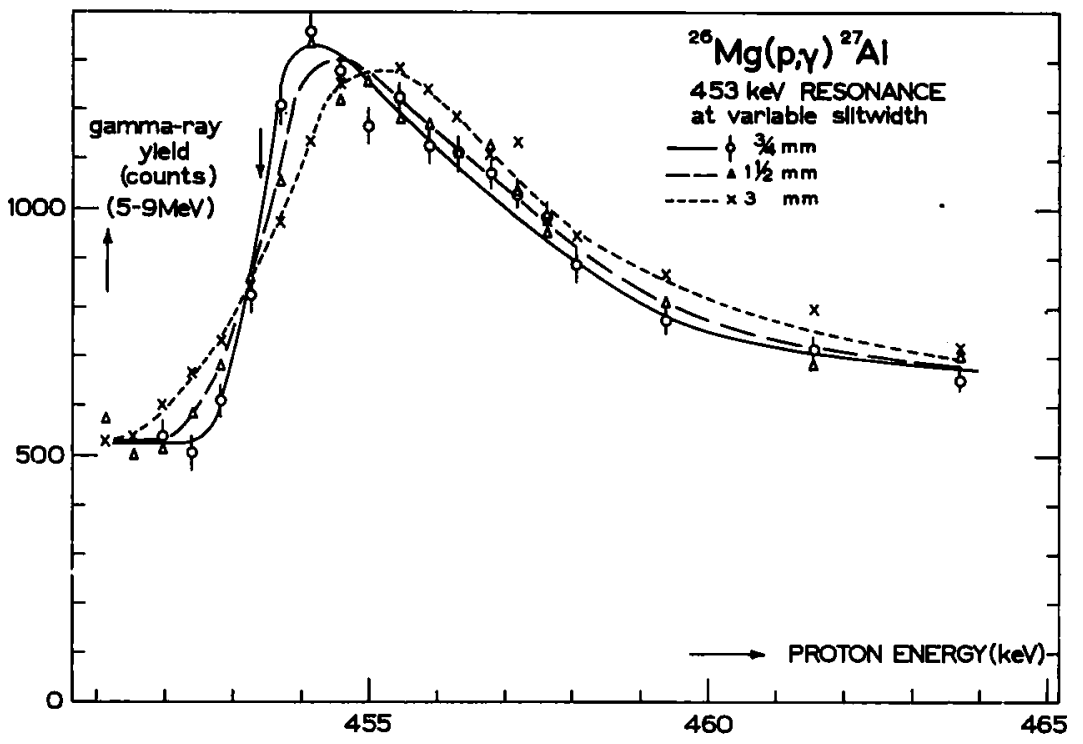

Fig. 1. Gamma-ray yield curves measured at the $453 \mathrm{keV}{ }^{26} \mathrm{Mg}(p, \gamma)^{27} \mathrm{Al}$ resonance with entrance and exit slits of the analysing magnet both equal to $0.75,1.5$, and $3.0 \mathrm{~mm}$, respectively. The half-maximum point on the low-energy slope indicated by an arrow is seen to be almost independent of slitwidth.

All resonances below $E_{p}=350 \mathrm{keV}$ and some resonances in the $350-425$ $\mathrm{keV}$ interval were measured with the $\mathrm{H}_{2}{ }^{+}$beam. It has been remarked by several authors ${ }^{3}{ }^{6}$ ) that this introduces an additional broadening of the front slope of the resonance, while also the resonance may be shifted to slightly lower energy. The second effect has also been observed in the present work but is certainly smaller than $0.1 \%$. The first effect is taken into account automatically by the procedure of error assignments indicated above. Of course, the mass of the electron in the $\mathrm{H}_{2}+$ ion has to be considered in the comparison of $\mathrm{H}_{2}{ }^{+}$and $\mathrm{H}_{1}{ }^{+}$resonance energies.

3. Calibration and results. All measured resonance energies are given in Table II, second column.

The resonances marked with an asterisk were used for the determination of the magnet calibration constant $K$. From each measured resonance frequency and the corresponding reference energy given in column 4 a $K$ value was computed with an error compounded from the observed inter- 
TABLE II

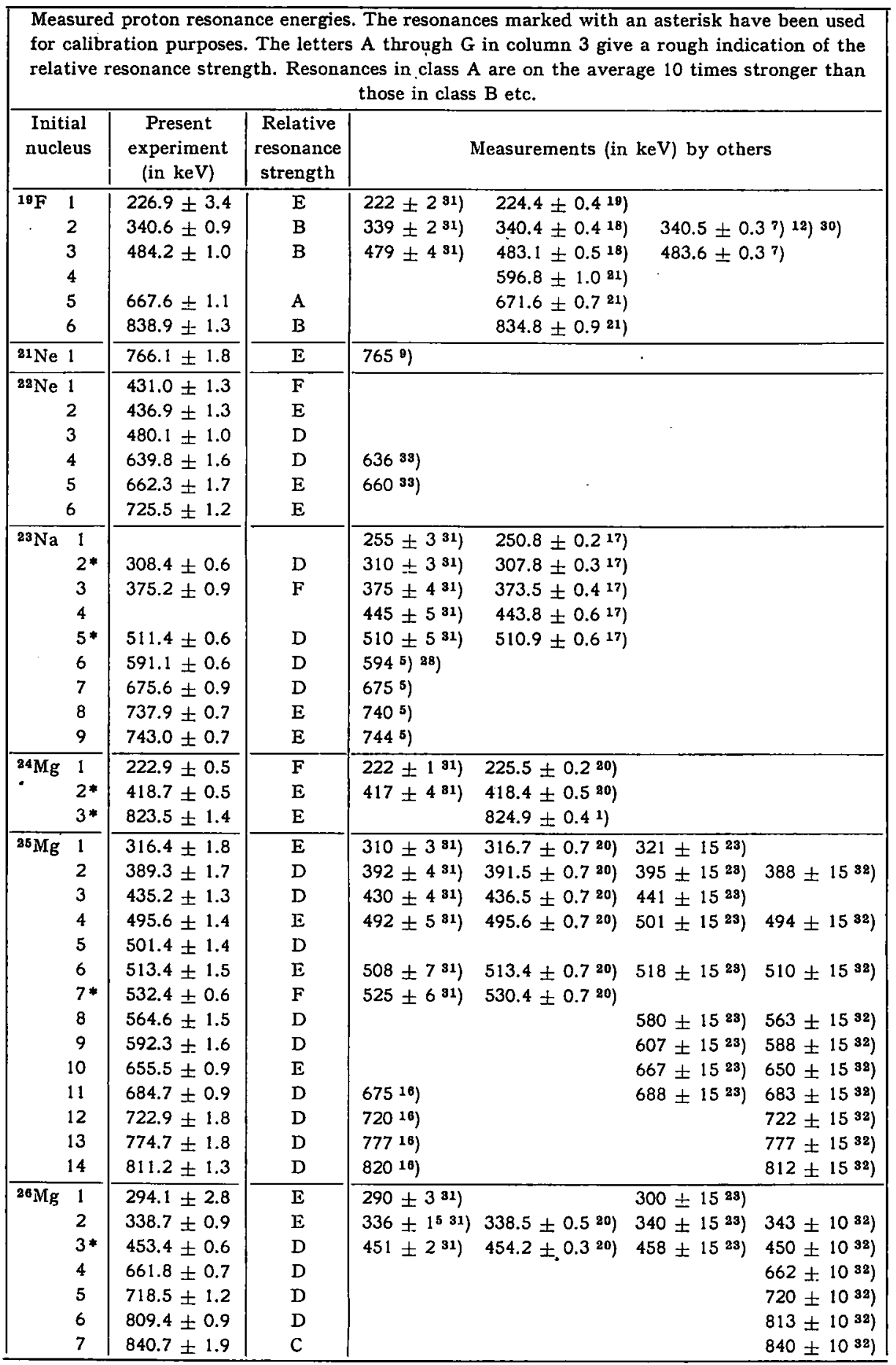


TABLE II (Continued)

\begin{tabular}{|c|c|c|c|c|c|c|}
\hline & \multirow{2}{*}{$\begin{array}{c}\begin{array}{c}\text { Present } \\
\text { experiment } \\
\text { (in keV) }\end{array} \\
224.1 \pm 0.7\end{array}$} & \multirow{2}{*}{$\begin{array}{c}\begin{array}{c}\text { Relative } \\
\text { resonance } \\
\text { strength }\end{array} \\
G\end{array}$} & \multicolumn{3}{|c|}{ Measurements (in keV) by others } \\
\hline \multirow[t]{17}{*}{${ }^{27} \mathrm{Al}$} & $\begin{array}{c}\text { Initial } \\
\text { nucleus }\end{array}$ & & & $\left.225 \pm 3^{31}\right)$ & \multirow{2}{*}{$\begin{array}{l}\left.226.3^{\prime} \pm 1.5^{19}\right) \\
\left.294.0^{19} \pm 5^{19}\right)\end{array}$} & \multirow{17}{*}{ - } \\
\hline & 2 & $294.8 \pm 4.0$ & G & $\left.295 \pm 3^{31}\right)$ & & \\
\hline & 3 & $327.5 \pm 0.8$ & $\mathbf{F}$ & $\left.325 \pm 3^{31}\right)$ & $\left.325.6 \pm 0.4^{19}\right)$ & \\
\hline & $4^{*}$ & $405.3 \pm 0.7$ & $\mathbf{F}$ & $404 \pm 3^{31}$ & $\left.404.7 \pm 0.4^{19}\right)$ & \\
\hline & 5 & $446.2 \pm 0.5$ & F & $443 \pm 5^{31}$ & $\left.438.5 \pm 0.5^{19}\right)$ & \\
\hline & $6 *$ & $504.0 \pm 0.5$ & E & $504.5 \pm 0.39)$ & \multirow{2}{*}{$\left.504.0 \pm 0 . \epsilon^{19}\right)$} & \\
\hline & $7^{*}$ & $506.1 \pm 0.5$ & $\mathbf{E}$ & $506.5 \pm 0.33)$ & & \\
\hline & $8^{*}$ & $611.0 \pm 0.6$ & F & $\left.612.4 \pm 1.0^{3}\right)$ & $\left.609 \pm 1.2^{10}\right)$ & \\
\hline & $9 *$ & $631.5 \pm 0.6$ & D & $\left.632.3^{\prime} \neq 0.3^{3}\right)$ & $\left.630 \pm 1.3^{10}\right)$ & \\
\hline & $10^{*}$ & $653.9 \pm 1.2$ & $\mathrm{D}$ & $\left.654.3 \pm 0.3^{3}\right)$ & $\left.652 \pm 1.3^{10}\right)$ & \\
\hline & $11^{*}$ & $678.3 \pm 1.2$ & $\mathrm{E}$ & $\left.677.6 \pm 1.0^{3}\right)$ & $\left.677^{\prime} \pm 1.4^{10}\right)$ & \\
\hline & $12 *$ & $730.7 \pm 0.7$ & D & $730.6 \pm 0.3 \mathrm{~s})$ & $\left.728 \pm 1.5^{10}\right)$ & \\
\hline & $13^{*}$ & $735.1 \pm 1.5$ & $\mathrm{D}$ & $735.6 \pm 0.3^{3}$ & $\left.733 \pm 1.5^{10}\right)$ & \\
\hline & $14^{*}$ & $742.4 \pm 1.0$ & $\mathrm{E}$ & $\left.741.1 \pm 0.7^{\mathrm{s}}\right)$ & $738 \pm 1.510)$ & \\
\hline & $15^{*}$ & $759.9 \pm 1.0$ & $\mathrm{E}$ & $\left.759.4 \pm 0.3^{3}\right)$ & $\left.757 \pm 1.5^{10}\right)$ & \\
\hline & $16^{*}$ & $766.7 \pm 1.0$ & D & $\left.766.3 \pm 0.3^{3}\right)$ & $\left.764 \pm 1.5^{10}\right)$ & \\
\hline & $17 *$ & $773.0 \pm 1.0$ & $\mathrm{D}$ & $\left.772.8 \pm 0.3^{3}\right)$ & $\left.771 \pm 1.5^{10}\right)$ & \\
\hline${ }^{28} \mathrm{Si}$ & 1 & $368.9 \pm 0.7$ & $\mathrm{D}$ & $367 \pm 431)$ & $\left.367 \pm 2^{36}\right)$ & \\
\hline \multirow[t]{4}{*}{$29 \mathrm{Si}$} & 1 & $326.4 \pm 1.2$ & $E$ & $326 \pm 3^{31}$ & $\left.\left.326^{24}\right)^{25}\right)$ & \\
\hline & 2 & $415.3 \pm 1.3$ & D & $\left.414 \pm 4^{31}\right)$ & $\left.\left.\left(414^{24}\right)^{25}\right) 11\right)$ & \\
\hline & 3 & $697.5 \pm 0.7$ & D & & $\left.\left.693^{24}\right)^{25}\right)^{11}$ & \\
\hline & 4 & $730.1 \pm 1.2$ & E & & $\left.\left(29^{24}\right)^{25}\right)^{11}$ & \\
\hline \multirow[t]{6}{*}{${ }^{30} \mathrm{Si}$} & $1 *$ & $498.3 \pm 1.0$ & $E$ & $499 \pm 5^{31}$ & $500^{111}$ & \\
\hline & 2 & $619.6 \pm 1.2$ & D & & $\left.625^{11}\right)$ & \\
\hline & 3 & $669.8 \pm 1.0$ & $\mathrm{~F}$ & & $67511)$ & \\
\hline & 4 & $759.3 \pm 0.9$ & E & & $760^{11)}$ & \\
\hline & 5 & $776.4 \pm 1.0$ & $\mathrm{D}$ & & $775^{11)}$ & \\
\hline & 6 & $834.2 \pm 1.3$ & E & & $\left.840^{11}\right)$ & \\
\hline \multirow[t]{6}{*}{ S1P } & $1^{*}$ & $\overline{354.8} \pm \overline{0.7}$ & $\mathrm{~F}$ & $355 \pm 4^{31}$ & & \\
\hline & $2 *$ & $438.7 \pm 0.9$ & F & $\left.440 \pm 5^{31}\right)$ & $\left.\left.440^{15}\right)^{22}\right)$ & \\
\hline & $3 *$ & $540.9 \pm 1.1$ & D & $540 \pm 631)$ & $\left.\left.540^{15}\right)^{22}\right)$ & \\
\hline & 4 & $641.3 \pm 0.8$ & $\mathrm{E}$ & & 648 15) 22) 14) & \\
\hline & 5 & $811.2 \pm 1.0$ & D & & $\left.\left.\left(816^{15}\right)^{22}\right)^{87}\right)$ & \\
\hline & 6 & $820.0 \pm 1.0$ & E & & $\left.325^{27}\right)$ & \\
\hline \multirow[t]{2}{*}{$\overline{32 \mathrm{~S}}$} & 1 & $579.8 \pm 1.1$ & $\mathrm{D}$ & $\left.579.8 \pm 1.5^{34}\right)$ & & \\
\hline & 2 & $587.3 \pm 1.1$ & D & $\left.587.4 \pm 1.5^{34}\right)$ & & \\
\hline \multirow[t]{2}{*}{ 39S } & 1 & $446.5 \pm 3.5$ & $\mathrm{E}$ & $\left.449 . \pm 10^{35}\right)$ & & \\
\hline & 2 & $507.1 \pm 1.0$ & D & $\left.513 \pm 10^{35}\right)$ & & \\
\hline
\end{tabular}

quartile range and the error given in the reference energy. Altogether twenty-nine reference energies were used for the calibration, of which ten are given by Tangen ${ }^{31}$ ), twelve by Andersen e.a. ${ }^{3}$ ), six by Hunt, Hancock and co-workers ${ }^{17-21}$ ), and one by Ager-Hanssen e.a. ${ }^{1}$ ). Weighted averages of the $K$ values were then computed in groups (see Table I) according to the authors from which the reference energies were taken, and an internal and external error was determined for each group average. It is seen that only for the reference energies given by $\mathrm{Hunt}$ e.a. the 
external error comes out slightly larger than the internal error. In all cases the largest of the two errors was taken as the final error in the corresponding group average. The error in the Andersen group average has been taken somewhat larger than both the internal and the external error to account for a $0.02 \%$ error in the $990.8 \mathrm{keV}{ }^{27} \mathrm{Al}(p, \gamma)$ resonance used by them for calibration, and for a $0.02 \%$ error resulting from possible non-linearity. Finally, a weighted average was computed of the group averages yielding: $K=945.9 \pm 0.4 \mathrm{MHz}^{2} / \mathrm{MeV}$. The external and internal error of this final average value were found to be equal. This calibration constant was used for the computation of all resonance energies given in Table II, column 2. To the errors assigned to the resonance energies contribute the experimental error (interquartile range) and the error in the calibration constant. The ${ }^{21} \mathrm{Ne}$ and ${ }^{22} \mathrm{Ne}$ measurements contain an additional uncertainty (not included), because it was not known how far the neon ions had penetrated into the nickel backing in the mass separator bombardment.

From the calibration constant the orbit radius in the magnet can be found yielding $r=20.004 \pm 0.004 \mathrm{~cm}$, in excellent agreement with the design value: $r=20 \mathrm{~cm}$.

In principle saturation of the magnet might cause a deviation from the proportionality between the average magnetic field on the orbit and the field at the position of the gaussmeter probe. No systematic difference, however, has been found for $K$ values from high-energy and from lowenergy resonances. Actually the magnetic field for $850 \mathrm{keV} \mathrm{H}_{1}{ }^{+}$and $\mathrm{H}_{2}{ }^{+}$ ions is 6700 and 9400 oersted, respectively, which is still far from saturation.

Some indication has been added in Table II column 3 as to the intensity of the resonances. Classes $A$ through $G$ roughly decrease in intensity by consecutive factors of 10 . In all measurements the same counter was used at the same distance from the target, at an angle of $55^{\circ}$ to the proton beam direction, the latter chosen to average out $\cos ^{2} \theta$ terms in angular distributions. All measured intensities were corrected for differences in chemical and isotopic composition of the targets used, and can thus (if differences in $\mathrm{d} E / \mathrm{d} x$ are neglected) be interpreted as the relative resonance strengths. However, discriminator settings have varied widely and furthermore the composition of the ${ }^{21} \mathrm{Ne}$ and ${ }^{22} \mathrm{Ne}$ targets was badly known, which made us decide to present only order of magnitude intensities.

The ${ }^{23} \mathrm{Na}$ resonances (1) and (4) were not observed in the present experiment. These resonances are indicated by $\mathrm{T}$ angen as weaker than resonance (3) which just barely could be detected. The ${ }^{19} \mathrm{~F}$ resonance (4) is very broad; no attempt has been made to determine its energy.

The ${ }^{22} \mathrm{Ne}(p, \gamma)^{23} \mathrm{Na}$ reaction shows three.strong and three weak resonances (see Fig. 2). Two of the stronger ones were found by Broström, $\mathrm{H}$ u us and $\mathrm{Koch}{ }^{9}$ ), and were later investigated in some detail by Thorn ton, Meads and Collie ${ }^{33}$ ). The other four resonances, at $431.0 \pm 1.3$, 
$436.9 \pm 1.3,480.1 \pm 1.0$, and $725.5 \pm 1.2 \mathrm{keV}$, were first observed in the present investigation with separated targets obtained both from Harwell

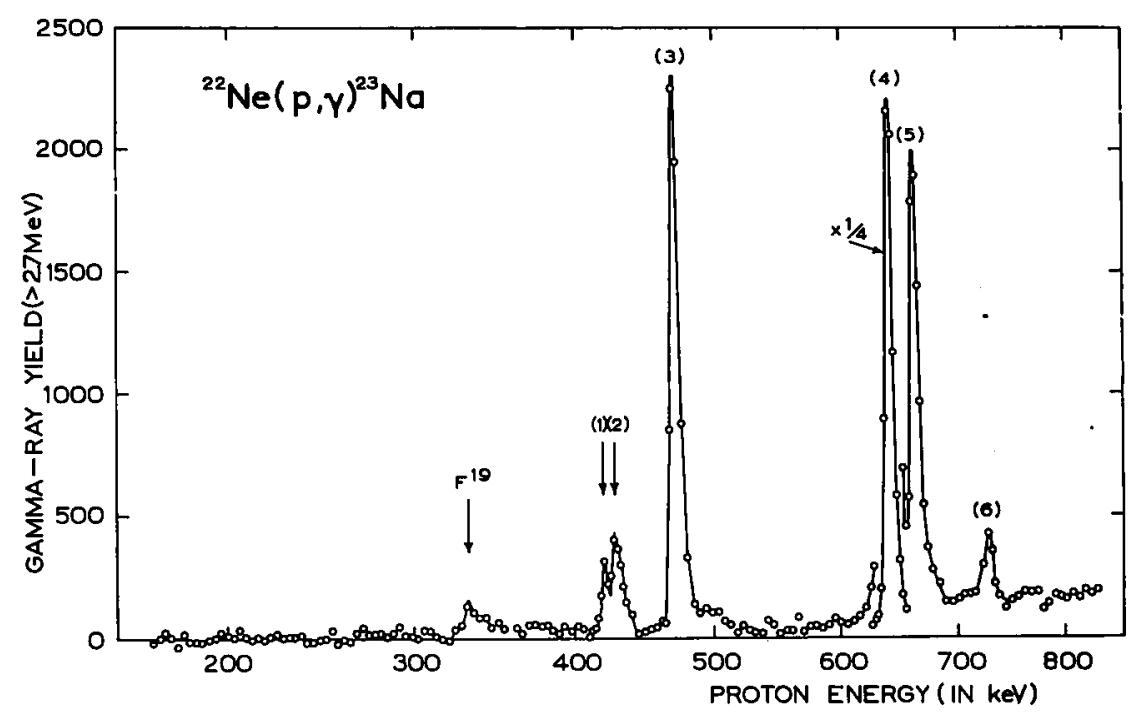

Fig. 2. Gamma-ray yield curve of the ${ }^{22} \mathrm{Ne}(p, \gamma)^{23} \mathrm{Na}$ reaction. The broad peak at about $320 \mathrm{keV}$ results from ${ }^{19} \mathrm{~F}$ contamination. The resonances numbered $1,2,3$, and 6 have not been observed before.

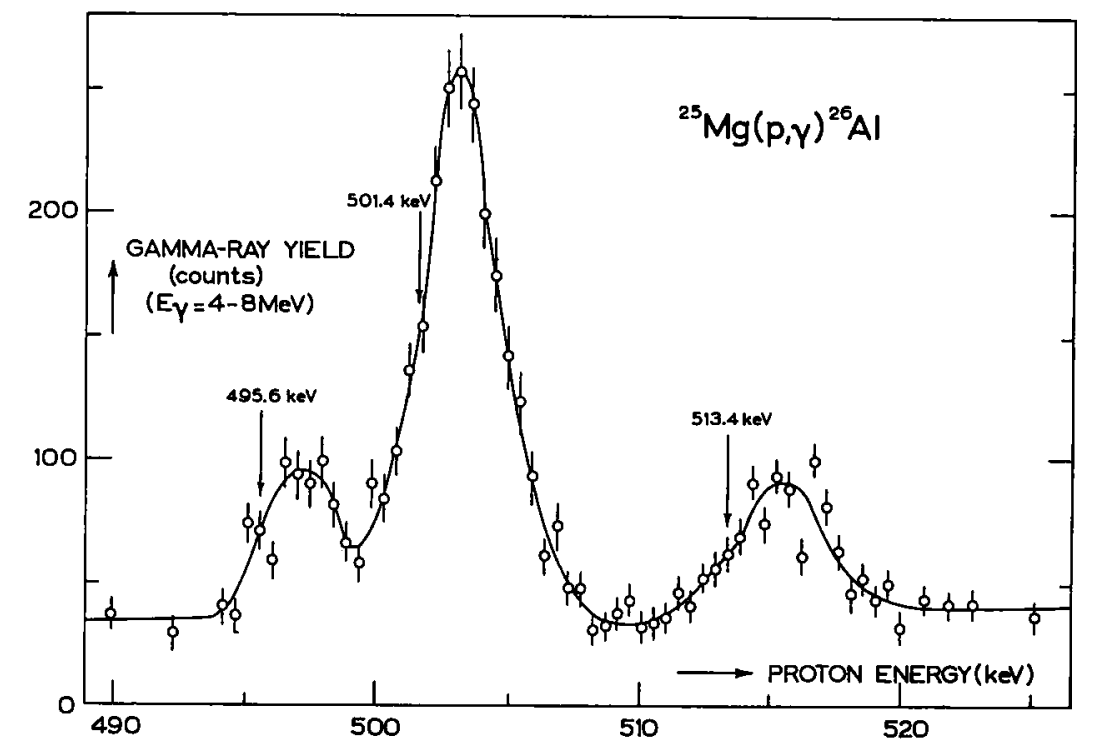

Fig. 3. Gamma-ray yield curve of the ${ }^{25} \mathrm{Mg}(p, \gamma)^{26} \mathrm{Al}$ reaction in the $E_{p}=490-525 \mathrm{kcV}$ region. The new resonance at $501.4 \mathrm{keV}$ is well resolved from that at $495.6 \mathrm{keV}$.

and from Amsterdam. The resonances numbered 1 through 4 (see Table II) have also been seen, with the same relative intensities, in bombardments 
of natural neon gas. In this case the maximum voltage of the generator was not high enough to observe resonance 6 , while the resonances 4 and 5 could not be resolved.

The ${ }^{25} \mathrm{Mg}$ resonances at 495.6 and $501.4 \mathrm{keV}$ have not been separated before. The assignment given here can be regarded as unique, however, because these resonances have been observed from several targets with constant relative intensities. In fig. 3 a ${ }^{25 \mathrm{Mg}}(p, \gamma)^{26} \mathrm{Al}$ yield curve is shown for the $E_{p}=490-525 \mathrm{keV}$ region.

The ${ }^{33} \mathrm{~S}$ measurements have not been extended above $550 \mathrm{keV}$. At least ten resonances have been observed in the $550-850 \mathrm{keV}$ region but the target was not quite thin enough to resolve these fully, while also part of them may have to be attributed to ${ }^{34} \mathrm{~S}$.

Acknowledgements. This investigation is part of the research program of the "Stichting voor Fundamenteel Onderzoek der "Materie", and was made possible by financial support from the "Nederlandse Organisatie voor Zuiver Wetenschappelijk Onderzoek".

Several of our colleagues have given active help during the measurements. Especially we want to thank Dr. C. van der Leun, who first surveyed the ${ }^{22} \mathrm{Ne}(p, \gamma)$ yield curve.

Received 5-3-59

\section{REFERENCES}

1) Ager-Hanssen, Lönsjö and Nordhagen, Phys. Rev. 101 (1956) 1779.

2) Ajzenberg, F, and Lauritsen, R., Revs. mod. Phys. 27 (1955) 77.

3) Andersen, Bö, Holtebekk, Lönsjö and Tangen, Nucl. Phys. 9 (1959) 509.

4) Andersen, Gjötterud, Holtebekk and Lönsjö, Nucl. Phys. 7 (1958) 384.

5) Baumann, Prosser, Read and Krone, Phys. Rev. 104 (1956) 376.

6) Bondelid, Butler and Kennedy, Bull. Am. phys. Soc. 2 (1957) 381.

7) Bondelid, Butler and Kennedy, private communication (1958).

8) Bonner, T. W. and Evans, J. E., Phys. Rev. 73 (1948) 666.

9) Broström, Huus and Koch, Nature 160 (1958) 480.

10) Broström, H u us and Tangen, Phys. Rev. 71 (1947) 661.

11) Broude, Green and Willmott, Proc. phys. Soc. (London) 72 (1958) 1097, 1115 and 1122.

12) Bumiller, St a u b and We a ver, Helv. phys. Acta 29 (1956) 83.

13) Endt, P. M. and Braams, C. M., Revs. mod. Phys. 99 (1957) 683.

14) Freeman, J. M. and Seed, J., Proc. phys. Soc. (London) A 64 (1951) 313 (L).

15) Grove, G. R. and Cooper, J. N., Phys. Rev, 82 (1951) 505.

16) Green, Sing b and Willmott, Proc. phys. Soc. (London) A 69 (1956) 335.

17) Hancock, D. A. and Verdaguer, F., Proc. phys. Soc. (London) A 68 (1955) 1080.

18) Hunt, S. E., Proc. phys. Soc. (London) 65 A (1952) 982.

19) Hunt, S. E. and Jones, W. M., Phys. Rev. 89 (1953) 1283.

20) Hunt, S. E. and Hancock, D. A., Pbys. Rev. 97 (1955) 567 (L).

21) Hunt, S. E. and Firth, K., Phys. Rev. 98 (1955) 786.

22) Kern, B. D. and Cochran, L. W., Phys. Rev. 104 (1956) 711.

23) Kluyver, Van der Leun and Endt, Physica 20 (1954) 1287. 
24) Kluyver, J. C. and Endt, P. M., Proceedings of the Conference on electromagnetically enriched isotopes, Harwell (1955).

25) Milani, Cooper and Harris, Phys. Rev. 99 (1955) 645 (A).

26) Morrish, A. H., Phys. Rev. 76 (1949) 1651.

27) Paul, Gove, Litherland and Bartholomew, Phys. Rev. 99 (1955) 1339.

28) Prosser, Bauman, Brice, Re ad and Krone, Phys. Rev. 104 (1956) 369.

29) Russel, Taylor and Cooper, Phys. Rev. 05 (1954) 99.

30) Staub, H., Nuovo Cimento Suppl. 6 (1957) 306.

31) Tangen, R., Det Kgl. Norske Videnskabers Selskabs Skrifter (1946).

32) Taylor, Russel and Cooper, Phys. Rev. 93 (1954) 1056.

33) Thornton, Meads and Collie, Phys. Rev. 109 (1958) 480.

34) Van der Leun, C. and Endt, P. M., Physica 24 (1958) 1095.

35) Van der Leun, C., thesis Utrecht (1958).

36) Van Oostrum, Alster, Hazewindus and Wapstra, Physica 24 (1958) 1051. 